\title{
HANNO COLLABORATO
}

\author{
ALLA QUINTA EDIZIONE ITALIANA \\ condotta sulla $\mathrm{II}^{\mathrm{a}}$ e $\mathrm{I}^{\mathrm{a}}$ edizioné tedesca
}

Volume Secondo, Parte Seconda

\section{LIBERI DOCENTI}

G. BAROLDI - S. BATTAGLIA - L. LOCATELLI

T. MASINI - I. MORETTI GUERCIO - D. PALAZZI - F. RILKE

A. TOMMASINI DEGNA - L. TROPEANO - M. ZORZI

$$
\text { E I DOTTORI }
$$

M. BRUNELLI - S. D'ANCONA - F. MORTILLARO 
